\title{
Complications in Facial Esthetic Surgery
}

\author{
Arya Namin, MD ${ }^{1}$ Tom Shokri, MD ${ }^{2}$ Aurora Vincent, MD ${ }^{2}$ Masoud Saman, MD \\ Yadranko Ducic, MD, FRCS(C), FACS ${ }^{2}$
}

${ }^{1}$ Department of Otolaryngology - Head and Neck Surgery, University of Missouri, Columbia, Missouri

2 Otolaryngology and Facial Plastic Surgery Associates, Fort Worth,

Texas

${ }^{3}$ Saman Center for Facial Plastic Surgery, Plano, Texas

Semin Plast Surg 2020;34:272-276.

\begin{abstract}
Keywords

- cosmetic surgery

- complications

- facial plastic surgery

- esthetic surgery
\end{abstract}

Address for correspondence Tom Shokri, MD, Otolaryngology and
Facial Plastic Surgery Associates, 923 Pennsylvania Avenue, Suite 100 Fort Worth, TX 76104 (e-mail: tom.shokri@gmail.com).
Facial esthetic surgery is challenging, and an intricate understanding of the form and function of the face is required both to obtain favorable outcomes and minimize complications. When considering surgery of the brow, upper eyelids, and lower eyelids the function of ocular protection must be kept in mind. In cosmetic rhinoplasty structural complications, soft tissue envelope compromise, and infections must be examined. In lower face and neck lift surgery injury to sub-superficial musculoaponeurotic system (SMAS) structures such as the facial nerve and salivary glands as well as infections and skin flap compromise. Lastly, in volume augmentation procedures such as hyaluronic acid (HA) filler and fat grafting, the complex vascular supply to the face including external-internal carotid artery collateral circulation must be kept in mind. In this article, we review the common complications encountered in periorbital rejuvenation, cosmetic rhinoplasty, lower face and neck rejuvenation, and particular complications that need to be considered for HA and fat grafting.

\section{Brow Lift}

There are various brow lift techniques, including direct, midforehead, hairline, temporal, coronal, and endoscopic. The patient's hairline and aging changes of the forehead and brow are typically the two guiding factors that lead to selection of technique. The common complications encountered in brow lifting include bleeding, anesthesia due to sensory nerve injury, paresis or paralysis due to temporal branch of facial nerve injury, scarring, alopecia, brow asymmetry, and over-/ underelevation of the brow. ${ }^{1}$ Each brow lifting technique has its own incidence of complications. ${ }^{2}$ In a systematic review of complications in brow lifting techniques, need for revisional surgery has been found to be highest in hairline $(7.4 \%)$ and direct (2.4\%) brow lift techniques. ${ }^{2}$ The incidence of asymmetry was highest in the temporal lift (1.5\%) and direct lifts (0.9\%). The rate of alopecia was highest in the coronal $(2.2 \%)$ and temporal (1.5\%) brow lifts. The most common complications encountered in endoscopic brow lifts were alopecia (2.8\%) and numbness (2\%). The incidence of nerve injury in endoscopic brow lift techniques was found to be $0.1 \%$ and was similarly low in the open brow lift techniques. ${ }^{2}$ This low incidence of temporal branch of facial nerve injury is due to the welldescribed anatomy of this branch of the facial nerve in the temporal region as it courses just deep to the temporoparietal fascia. ${ }^{3}$ So long as the dissection plane in the temporal region is immediately superficial to the superficial layer of the deep
Issue Theme Complications and Secondary Management and Repair in Head, Neck and Plastic Surgery; Guest Editor: Yadranko Ducic, MD, FRCS(C), FACS
Copyright $\odot 2020$ by Thieme Medical Publishers, Inc., 333 Seventh Avenue, 18th Floor, New York, NY 10001, USA Tel: +1(212) 760-0888.
DOI https://doi.org/ 10.1055/s-0040-1721764. ISSN 1535-2188. 
temporal fascia, the temporal branch of the facial nerve can be reliably avoided. Temporary peri-incisional numbness should be expected; however, anesthesia of the forehead and scalp can be avoided with preserving the supraorbital and supratrochlear neurovascular bundles. The safety profile of the various brow lifting techniques are favorable. ${ }^{4,5}$

\section{Upper Lid Blepharoplasty}

An understanding of the form and function of the upper eyelid as well as the pathophysiology of various disease states that affect the upper eyelid will allow the cosmetic surgeon to design and execute an operative plan that addresses each individual patient's anatomy. A history and physical exam will identify contributing factors to the patient's cosmetic concerns. A history of dry eye and prior ocular surgery particularly LASIK surgery should be elicited. It is typically recommended to delay blepharoplasty for 6 months after LASIK surgery. Any contribution from brow ptosis should be carefully examined and discussed with the patient. The margin reflex distance 1 (MRD1), MRD2, fissure width, margin crease distance, and measurement of levator function should all be examined preoperatively. ${ }^{6}$ Identifying blepharoptosis prior to embarking on blepharoplasty is of the utmost importance, and this is typically characterized by an MRD1 of less than 4 to $4.5 \mathrm{~mm}$ and margin crease distance greater than 9 to $11 \mathrm{~mm}$. According to Hering's law, if a unilateral ptosis is identified, the visual input to the affected eye should be obstructed to identify a contralateral ptosis that may become unmasked after unilateral repair. ${ }^{7}$ Examining the volumetric characterization of the upper eyelid will also allow the cosmetic surgeon to tailor the approach to the patient's individual anatomy. ${ }^{8}$ Careful preoperative assessment of patients prior to upper eyelid blepharoplasty will allow the surgeon to avoid complications such as residual upper lid skin, eyelid ptosis, and brow ptosis. ${ }^{9}$ Operative planning and precise preoperative marking can help avoid superior sulcus deformity, eyelid crease asymmetry, canthal webbing, and lagophthalmos. Canthal webbing can occur when the excision is taken too far medially past the medial canthus or extended inferiorly nearing the lid margin. Intraoperative complications such as globe penetration can be prevented by never directing a needle toward the globe, and if this complication is encountered immediate consultation with an ophthalmologist should be sought out. ${ }^{9}$ Postoperatively, an eye care regimen can help decrease the risks of chemosis and corneal erosion, although these should be carefully monitored for. ${ }^{10}$ Lacrimal gland injury, canalicular injury, preseptal and postseptal cellulitis are all complications that must be considered. ${ }^{9,10}$ The risk of retrobulbar hematoma and vision loss is rare, but is estimated to occur in approximately $0.0052 \%$ of cases based on a survey study. ${ }^{11}$ If retrobulbar hematoma is encountered, immediate orbital decompression should be performed through lateral canthotomy and cantholysis. Despite the many possible complications of blepharoplasty, a comprehensive history and physical exam followed by precise operative planning and execution can lead to reproducible results. ${ }^{12}$

\section{Lower Lid Blepharoplasty}

Lower eyelid blepharoplasty has two primary techniques, a transcutaneous and a transconjunctival. The technique utilized is based on a combination of surgeon preference, patient anatomy, and additional procedures (midface lift, lower face and neck lift, and fat grafting) that will be completed in the same setting to best achieve a smooth transition between the lower eyelid and midface. Lower eyelid blepharoplasty is an inherently difficult esthetic surgery due to concomitant tarsoligamentous laxity that is commonly encountered in the aging face population. An attentive preoperative examination can help guide a surgeon to design an operative plan that minimizes the risk of lower lid malposition and ectropion postoperatively. The position of the lower lid, the canthal tilt, and presence of scleral show preoperatively should be identified. The degree of tarsoligamentous laxity can be assessed by the snapback test and lid distraction test. The degree of eye prominence should be assessed with a Hertel exophthalmometer and measured, and the presence of negative vector (most anterior component of the malar tissue is found posterior to the most anterior projection of the globe) should be identified. ${ }^{13}$ Patients with prominent eyes and negative vectors are particularly prone to lower lid malposition postoperatively, and therefore require thoughtful planning and execution of lateral canthal and midface procedures. ${ }^{13}$ Many authors would argue that routine support of the lower lid through a canthopexy procedure should be considered on a routine basis, and that patients with more severe tarsoligamentous laxity or preoperative scleral show or ectropion be considered for canthoplasty. ${ }^{13-15}$ Despite best efforts in preventing lower eyelid retraction and ectropion, these are known complications of lower eyelid blepharoplasty. ${ }^{16}$ The treatment of postblepharoplasty lower eyelid retraction and ectropion are challenging pathologies to address. ${ }^{17}$ While many would agree that transcutaneous blepharoplasty poses an increased risk of postblepharoplasty lower eyelid retraction and ectropion compared with transconjunctival approached, if appropriate pre-emptive measures are taken to support the tarsoligamentous sling the transcutaneous approach can be safe and reliable. ${ }^{13,14,17}$ Preoperative analysis of the lower eyelid midface junction, and execution of an operative plan with the goal of creating a smooth transition between these facial subunits is important in preventing volume depletion of the lower eyelid. ${ }^{16}$ Concomitant midface lift, lower face and neck lift, fat grafting, and fat transposition are all techniques that can be employed to minimize the risk of volume depletion in this facial subunit. ${ }^{16,18-20}$ Chemosis, an infiltrative edema of the conjunctiva can be seen after lower lid blepharoplasty. ${ }^{21}$ Despite the technical demands of lower eyelid blepharoplasty, reproducible outcomes can be achieved, although the longevity of these results are poorly understood in the literature. ${ }^{22}$

\section{Facelift}

Facelift as an operation has evolved significantly over the past 50 years due to our increased understanding of facial anatomy and the pathophysiology of aging. ${ }^{23-27}$ Most facial esthetic 
surgeons would agree that our ability to manipulate the SMAS, augment volume, and contour sub-SMAS neck structures has improved esthetic outcomes. ${ }^{28-32}$ The quest to minimize complications in facelift surgery continues to this day. As in all cosmetic surgery, a critical history and physical examination is the first step in avoiding complications in face lift surgery. Medical history, surgical history, tobacco use, and patient goals should be discussed. ${ }^{33}$ A comprehensive esthetic facial analysis should be performed, and physical exam findings such as skin tone, skin thickness, rhytid characteristics, microgenia, and hyoid bone position should be noted. ${ }^{33}$ Sound surgical technique with release of retaining ligaments and leaving minimal to zero tension on the skin closure can help minimize complications such as hypertrophic scars, skin loss, hairline malposition, and changes in ear lobe position. ${ }^{33,34}$ The vector of skin redraping is important to consider so that late postoperative complications such as vertical sweep deformity can be avoided. ${ }^{35}$ Salivary fistula is a relatively rare complication, but can be encountered in face lifting surgery, particularly when ptotic submandibular glands are partially excised. ${ }^{29,36}$ Injury to the greater auricular nerve is the most common nerve injury, and injury to the marginal mandibular nerve is the most common motor nerve injury. ${ }^{33,34,37}$ Infections and deep vein thrombosis are both rare in face lift surgery, but are serious problems when encountered. ${ }^{37,38}$

The data are not clear on what techniques are associated with worse safety profiles, but it does appear that certain techniques are associated with particular complications. ${ }^{39,40}$ In a systematic review high lateral SMAS and composite techniques were found to have a 1.85 and 1.52 rate of temporary facial nerve injury, respectively, which was significantly greater than the $0.69 \%$ rate of temporary facial nerve injury in SMAS plication techniques. ${ }^{40}$ The rate of major hematoma was significantly higher in deep plane (1.22\%) and SMASectomy (1.92\%) compared with SMAS plication $(0.73 \%) .{ }^{40}$ Minimizing the risk of hematoma formation has been a goal of facial cosmetic surgeons for decades. ${ }^{41-46}$ The use of fibrin glue in facelift surgery has been studied for decades, and a recent review found data to support that fibrin glue does decrease the risk of hematoma. ${ }^{43}$ The utilization of drains has similarly been studied for decades, and there is evidence to support drains decrease the risk of seroma formation. ${ }^{44}$ Many would contend that drains also minimize postoperative edema. More recently, the effect of tranexamic acid (both topically and systemically) on bleeding, bruising, drain output, and hematoma has been studied, and appears to have promising utility in facial cosmetic surgery. ${ }^{42,46}$ Postoperative hematoma following face lift surgery is such a serious concern, that more aggressive techniques such as the hemostatic net have been proposed. ${ }^{41}$ Lastly, a very rare but dramatic complication follow facelift is pyoderma gangrenosum, an idiopathic inflammatory disease beginning with painful skin nodules that progress to ulcerations frequently in areas of trauma or surgery. ${ }^{47}$

\section{Rhinoplasty}

Many surgeons have dedicated their careers to rhinoplasty. This is a complex operation, and each maneuver incorporated into a rhinoplasty operation has implications on form and function. Complications in rhinoplasty can be broken down into structural complications, soft tissue envelope complications, bleeding, infectious, and systemic medical complications.

Structural complications in rhinoplasty are many and include skull base injuries, septal perforations, nasal airway dysfunction, graft malposition, graft absorption, graft visibility, saddle nose deformity, and persistent or knew deformities that require revisional surgery. These structural complications may become apparent during the early postoperative period or years later, indicating the importance of long-term follow-up and critical analysis of results even years after the operation. Skin necrosis and unsightly scars are the primary concerns regarding the soft tissue envelope. Rib grafts may be indicated in revisional esthetic rhinoplasty surgery. Although low, the complications to consider in autologous rib grafts include warping (3.08\%), resorption $(0.22 \%)$, infection $(0.56 \%)$, displacement (0.39\%), hypertrophic chest scarring (5.45\%), and revisional surgery (14.07\%). ${ }^{48}$ The risk of pneumothorax needs to be considered; however, a review of 405 patients from 8 studies found a $0 \%$ incidence of pneumothorax. ${ }^{48}$ Various alloplastic grafts, such as silicone, Gore-Tex, and Medpor, have been utilized in rhinoplasty. ${ }^{49}$ The overall rate of complications in alloplastic materials has been found to be $8 \%{ }^{49}$ While the rate of complications seen in alloplastic materials used in rhinoplasty may seem reasonable, these complications can often times include disastrous soft tissue envelope compromise that make many surgeons trepidatious about incorporating alloplastic grafts into their rhinoplasty practice. A recent review has found the most common complications after aesthetic rhinoplasty to be hematoma $(0.2 \%)$ and infection $(0.2 \%)$ with an overall complication rate of $0.7 \%{ }^{50}$ It was also found that age $\geq 40$ years increased the relative risk of complications, and that addition of other cosmetic surgeries concurrently with rhinoplasty increased the risk of pulmonary complications. ${ }^{50}$ Although rare, the rhinoplasty surgeon must be prepared to address epistaxis and septal hematoma postoperatively. Albeit rare, toxic shock syndrome has been reported after rhinoplasty in both patients with and without nasal packing. ${ }^{51,52}$ While perioperative antibiotic use during rhinoplasty is largely surgeon preference, review of the data available in the literature seems to support that perioperative antibiotic use does not improve outcomes. ${ }^{53,54}$

\section{Volume Augmentation}

As our understanding of facial aging has improved, the importance of volume restoration has been recognized. ${ }^{55}$ Volume augmentation in the head and neck region includes HA fillers, fat grafting, and implants. When considering complications of HA fillers and fat grafting the vascular anatomy of the head and neck must be considered. Complications such as blindness and stroke can be seen in volume augmentation procedures using HA fillers due to the collateral circulation between the external and internal carotid arteries. ${ }^{56}$ Vascular infarction of the soft tissues of the face can also be encountered. An understanding of this anatomy can help minimize these risks. ${ }^{56,57}$ Additional strategies to minimize risk in HA filler injections include slow injections, low pressure injections, movement of tip with 
delivery of product, use a small syringe and needle or blunt tip cannulas, and always monitor the patient. ${ }^{58}$ Certain areas of the face, such as the glabella, alar base, nose, and temple, are associated with risks of vascular complications. ${ }^{58,59}$ Esthetic providers that perform HA filler injections should keep a tool kit on hand for managing complications, should they arise. ${ }^{58}$ Aside from vascular complications, allergic reactions, infection, inappropriate placement, and inflammatory and noninflammatory nodules can be encountered. ${ }^{58}$ Contour irregularities, overcorrection, undercorrection, and persistent edema are complications that can be seen after facial fat grafting. As seen in HA fillers, blindness and stroke can occur in fat grafting. ${ }^{19}$ Genioplasty is a common esthetic procedure, and complications such as unsightly scars, cellulitis, orocutaneous fistulas, skin necrosis, metal nerve damage, chin ptosis, mentalis muscle dysfunction, tooth root disruption, mandibular bone resorption, and implant malposition can be encountered. $^{60}$

\section{Conclusion}

The facial esthetic surgeon must be prepared to manage a myriad of complications. Understanding the form and function of the head and neck, a thorough history and physical exam, comprehensive preoperative discussion regarding patient goals, thoughtful surgical planning, and meticulous execution can help minimize these complications.

Conflicts of Interest

None declared.

\section{References}

1 Lighthall JG, Wang TD. Complications of forehead lift. Facial Plast Surg Clin North Am 2013;21(04):619-624

2 Cho M-J, Carboy JA, Rohrich RJ. Complications in brow lifts: a systemic review of surgical and nonsurgical brow rejuvenations. Plast Reconstr Surg Glob Open 2018;6(10):e1943

3 Trinei FA, Januszkiewicz J, Nahai F. The sentinel vein: an important reference point for surgery in the temporal region. Plast Reconstr Surg 1998;101(01):27-32

4 Rohrich RJ, Cho M-J. Endoscopic temporal brow lift: surgical indications, technique, and 10-year outcome analysis. Plast Reconstr Surg 2019;144(06):1305-1310

5 Keller GS, Mashkevich G. Endoscopic forehead and brow lift. Facial Plast Surg 2009;25(04):222-233

6 Fagien S. Putterman's Cosmetic Oculoplastic Surgery E-Book. Philadelphia, PA: Saunders-Elsevier; 2007

7 Pan E, Yu J, Zhang S, Nie Y, Li Q. Retrospective analysis of the effect of Hering's law on outcomes of surgical correction of ptosis. Ann Plast Surg 2018;80(03):242-244

8 Glasgold M, Lam SM, Glasgold R. Volumetric rejuvenation of the periorbital region. Facial Plast Surg 2010;26(03):252-259

9 Whipple KM, Korn BS, Kikkawa DO. Recognizing and managing complications in blepharoplasty. Facial Plast Surg Clin North Am 2013;21(04):625-637

10 Baek JS, Kim KH, Lee JH, Choi HS. Ophthalmologic complications associated with oculofacial plastic and esthetic surgeries. J Craniofac Surg 2018;29(05):1208-1211

11 Mejia JD, Egro FM, Nahai F. Visual loss after blepharoplasty: incidence, management, and preventive measures. Aesthet Surg J 2011;31(01):21-29
12 Alghoul M. Blepharoplasty: anatomy, planning, techniques, and safety. Aesthet Surg J 2019;39(01):10-28

13 MD MAC. MD CDM Jr. Eyelid and Periorbital Surgery. 2nd ed. Boca Raton, FL: CRC Press; 2016

14 Rohrich RJ, Mohan R. Preventing lateral canthal malposition in modern blepharoplasty. Plast Reconstr Surg 2020;145(02): $324 \mathrm{e}-328 \mathrm{e}$

15 Harounian J, Wulc AE, Brackup AB, Ramesh S. Subtle eyelid retraction after lower blepharoplasty. J Plast Reconstr Aesthet Surg 2019;72(10):1682-1687

16 Schwarcz RM, Kotlus B. Complications of lower blepharoplasty and midface lifting. Clin Plast Surg 2015;42(01):63-71

17 Patel A, Wang Y, Massry GG. Management of postblepharoplasty lower eyelid retraction. Facial Plast Surg Clin North Am 2019;27 (04):425-434

18 Massry GG, Azizzadeh B. Periorbital fat grafting. Facial Plast Surg 2013;29(01):46-57

19 Maamari RN, Massry GG, Holds JB. Complications associated with fat grafting to the lower eyelid. Facial Plast Surg Clin North Am 2019;27(04):435-441

20 Jacono AA. A novel volumizing extended deep-plane facelift: using composite flap shifts to volumize the midface and jawline. Facial Plast Surg Clin North Am 2020;28(03):331-368

21 Patrocinio TG, Loredo BAS, Arevalo CEA, Patrocinio LG, Patrocinio JA. Complications in blepharoplasty: how to avoid and manage them. Rev Bras Otorrinolaringol (Engl Ed) 2011;77(03):322-327

22 Wilson SC, Daar DA, Maliha SG, Abdou SA, Levine SM, Baker DC. Lower eyelid blepharoplasty: does the literature support the longevity of this procedure? Aesthet Surg J 2018;38(12): 1289-1297

23 Mitz V, Peyronie M. The superficial musculo-aponeurotic system (SMAS) in the parotid and cheek area. Plast Reconstr Surg 1976;58 (01):80-88

24 Stuzin JM, Baker TJ, Gordon HL. The relationship of the superficial and deep facial fascias: relevance to rhytidectomy and aging. Plast Reconstr Surg 1992;89(03):441-449, discussion 450-451

25 Furnas DW. The retaining ligaments of the cheek. Plast Reconstr Surg 1989;83(01):11-16

26 Hamra ST. The deep-plane rhytidectomy. Plast Reconstr Surg 1990;86(01):53-61, discussion 62-63

27 Mendelson BC. Extended sub-SMAS dissection and cheek elevation. Clin Plast Surg 1995;22(02):325-339

28 Rohrich RJ, Narasimhan K. Long-term results in face lifting: observational results and evolution of technique. Plast Reconstr Surg 2016;138(01):97-108

29 Auersvald A, Auersvald LA. Management of the submandibular gland in neck lifts: indications, techniques, pearls, and pitfalls. Clin Plast Surg 2018;45(04):507-525

30 Jacono A, Bryant LM. Extended deep plane facelift: incorporating facial retaining ligament release and composite flap shifts to maximize midface, jawline and neck rejuvenation. Clin Plast Surg 2018;45(04):527-554

31 Marten T, Elyassnia D. Management of the platysma in neck lift. Clin Plast Surg 2018;45(04):555-570

32 Feldman J. Neck Lift. St. Louis, MO: Quality Medical Publishing; 2006

33 Fedok FG. The avoidance and management of complications, and revision surgery of the lower face and neck. Clin Plast Surg 2018; 45(04):623-634

34 Batniji RK. Complications/sequelae of neck rejuvenation. Facial Plast Surg Clin North Am 2014;22(02):317-320

35 Jacono AA, Malone MH. Vertical sweep deformity after face-lift. JAMA Facial Plast Surg 2017;19(02):155-156

36 Lawson GA III, Kreymerman P, Nahai F. An unusual complication following rhytidectomy: iatrogenic parotid injury resulting in parotid fistula/sialocele. Aesthet Surg J 2012;32(07):814-821

37 Cristel RT, Irvine LE. Common complications in rhytidectomy. Facial Plast Surg Clin North Am 2019;27(04):519-527 
38 Reinisch JF, Bresnick SD, Walker JW, Rosso RF. Deep venous thrombosis and pulmonary embolus after face lift: a study of incidence and prophylaxis. Plast Reconstr Surg 2001;107(06): 1570-1575, discussion 1576-1577

39 Chang S, Pusic A, Rohrich RJ. A systematic review of comparison of efficacy and complication rates among face-lift techniques. Plast Reconstr Surg 2011;127(01):423-433

40 Jacono AA, Alemi AS, Russell JL. A meta-analysis of complication rates among different SMAS facelift techniques. Aesthet Surg J 2019;39(09):927-942

41 Auersvald A, Auersvald LA. Hemostatic net in rhytidoplasty: an efficient and safe method for preventing hematoma in 405 consecutive patients. Aesthetic Plast Surg 2014;38(01):1-9

42 Cohen JC, Glasgold RA, Alloju LM, Glasgold MJ. Effects of intravenous tranexamic acid during rhytidectomy: a randomized, controlled, double-blind pilot study. Aesthet Surg J 2020:sjaa072. Doi: $10.1093 / \mathrm{asj} / \mathrm{sjaa072}$

43 Killion EA, Hyman CH, Hatef DA, Hollier LH Jr, Reisman NR. A systematic examination of the effect of tissue glues on rhytidectomy complications. Aesthet Surg J 2015;35(03):229-234

44 Perkins SW, Williams JD, Macdonald K, Robinson EB. Prevention of seromas and hematomas after face-lift surgery with the use of postoperative vacuum drains. Arch Otolaryngol Head Neck Surg 1997;123(07):743-745

45 Jones BM, Grover R. Avoiding hematoma in cervicofacial rhytidectomy: a personal 8-year quest. Reviewing 910 patients. Plast Reconstr Surg 2004;113(01):381-387, discussion 388-390

46 Schroeder RJ II, Langsdon PR. Effect of local tranexamic acid on hemostasis in rhytidectomy. Facial Plast Surg Aesthet Med 2020; 22(03):195-199

47 Niamtu J III. Pyoderma gangrenosum after facelift and otoplasty surgery: case presentations and literature review. J Oral Maxillofac Surg 2019;77(04):834-842

48 Wee JH, Park M-H, Oh S, Jin H-R. Complications associated with autologous rib cartilage use in rhinoplasty: a meta-analysis. JAMA Facial Plast Surg 2015;17(01):49-55

49 Liang X, Wang K, Malay S, Chung KC, Ma J. A systematic review and meta-analysis of comparison between autologous costal cartilage and alloplastic materials in rhinoplasty. J Plast Reconstr Aesthet Surg 2018;71(08):1164-1173

50 Layliev J, Gupta V, Kaoutzanis C, et al. Incidence and preoperative risk factors for major complications in aesthetic rhinoplasty: analysis of 4978 patients. Aesthet Surg J 2017;37(07):757-767

51 Wagner R, Toback JM. Toxic shock syndrome following septoplasty using plastic septal splints. Laryngoscope 1986;96(06): 609-610

52 Jacobson JA, Kasworm EM. Toxic shock syndrome after nasal surgery. Case reports and analysis of risk factors. Arch Otolaryngol Head Neck Surg 1986;112(03):329-332

53 Ishii LE, Tollefson TT, Basura GJ, et al. Clinical practice guideline: improving nasal form and function after rhinoplasty executive summary. Otolaryngol Head Neck Surg 2017;156(02):205-219

54 Nuyen B, Kandathil CK, Laimi K, Rudy SF, Most SP, Saltychev M. Evaluation of antibiotic prophylaxis in rhinoplasty: a systematic review and meta-analysis. JAMA Facial Plast Surg 2019;21(01): 12-17

55 Rohrich RJ, Ghavami A, Constantine FC, Unger J, Mojallal A. Liftand-fill face lift: integrating the fat compartments. Plast Reconstr Surg 2014;133(06):756e-767e

56 Cotofana S, Lachman N. Arteries of the face and their relevance for minimally invasive facial procedures: an anatomical review. Plast Reconstr Surg 2019;143(02):416-426

57 Cotofana S, Schenck TL, Trevidic P, et al. Midface: clinical anatomy and regional approaches with injectable fillers. Plast Reconstr Surg 2015;136(5, Suppl):219S-234S

58 Signorini M, Liew S, Sundaram H, et al;Global Aesthetics Consensus Group. Global aesthetics consensus: avoidance and management of complications from hyaluronic acid fillers-evidence- and opinion-based review and consensus recommendations. Plast Reconstr Surg 2016;137(06):961e-971e

59 Bertossi D, Giampaoli G, Verner I, Pirayesh A, Nocini R, Nocini P. Complications and management after a nonsurgical rhinoplasty: a literature review. Dermatol Ther (Heidelb) 2019;32(04): e12978

60 White JB, Dufresne CR. Management and avoidance of complications in chin augmentation. Aesthet Surg J 2011;31(06):634-642 